\title{
ESTUDIOS
}

\section{La investigación social en el horizonte de la misión de la Compañía de Jesús}

\section{Patxi Álvarez de los Mozos S. I.}

Palabras clave: Compañía de Jesús, investigación social, apostolado intelectual, liderazgo apostólico, misión fe-justicia.

Key words: Society of Jesus (Jesuits), social research, intellectual apostolate, apostolic leadership, mission of faith-justice.

Mots-clés: Compagnie de Jésus, recherche sociale, apostolat intellectuel, leadership apostolique, mission foi-justice.

\section{Introducción}

La misión de la Compañía de Jesús hoy consiste en la defensa de la fe y la promoción de la justicia en diálogo con la cultura y con otras tradiciones religiosas. Se trata de una formulación atrevida y brillante, llena de promesas y a la que aún no hemos respondido con todas las posibilidades con que cuenta nuestro cuerpo apostólico. Fe y justicia, sin poder separar la una de la otra. Nuestra fertilidad apostólica recae sobre cómo sostenemos con valentía esta misión recibida².

\footnotetext{
1 Patxi Álvarez de los Mozos es ingeniero técnico superior de Telecomunicaciones y director adjunto de la ONGD Alboan, Bilbao.

${ }^{2}$ Esta misión en realidad no es nuestra, sino de Cristo (CG 34, decreto 1) (La abreviatura CG se utilizará en lugar de "Congregación General"). Él nos la confía a nosotros, y también a otras muchas personas. $\mathrm{Ni}$ es de nuestra propiedad, ni la llevamos adelante nosotros solos. Concebirla de esta manera permite
} 
Sin embargo, todavía nos quedan bastantes consecuencias que extraer para esta misión por la fe y la justicia en todos los campos apostólicos en los que trabajamos. Nos cuesta mucho hacerlo, porque es muy exigente y comprometida. Necesita mucha oración, mucho desprendimiento, mucha creatividad, sabiduría, pasión, cercanía a los pobres, confesar y pedir perdón por nuestras alianzas afectivas con sus opositores... Es decir, requiere una profunda conversión, y la conversión se nos hace muy cuesta arriba. El padre Arrupe percibió esta necesidad de cambio con una claridad nítida, que nosotros continuamos lejos de alcanzar. Pues bien, la investigación social tiene mucho que aportar a esta misión de la fe que obra la justicia del Reino; de una justicia que anuncia lo más luminoso de la fe. De manera que este tema resulta muy relevante, al tiempo que exigente.

Si la Compañía es misión, de tal manera que precisamente en función de la misión reciben su ubicación adecuada todos los demás componentes de la vida religiosa (comunidad, oración, coro, Eucaristía, pobreza, obediencia...), esta misma misión deberá ayudarnos a colocar en su puesto a la investigación social. Este es el único hilo conductor que voy a seguir en esta intervención: qué lugar debe ocupar la investigación social en un cuerpo que ha hecho de la misión fe-justicia su último compromiso.

En esta intervención daré los siguientes pasos: revisaré las fuentes ignacianas que motivan el apostolado intelectual que ha estado presente en nuestra tradición histórica; a continuación trataré de mostrar que la misión actual de la Compañía demanda un conocimiento riguroso y sapiencial de la realidad; mencionaré que este conocimiento debe estar al servicio del liderazgo apostólico; describiré algunas dificultades actuales que nos encontraremos al desarrollar esta tarea; señalaré algunos campos que en el día de hoy podrían tener un interés especial; finalmente, incluiré un modelo que podría vehicular las intuiciones que a lo largo del texto irán apareciendo.

\section{El apostolado intelectual en nuestra historia}

La investigación social forma parte de un apostolado de profunda raigambre en la Compañía, el apostolado intelectual, que ha constituido un campo apostólico

abrir nuevos horizontes a la colaboración y situar ésta de manera adecuada, sin subordinación de ninguna persona. 
fundamental de nuestra misión desde sus inicios ${ }^{3}$. Los jesuitas, desde los primeros compañeros que eran "maestros en artes", han cultivado muchos campos del saber y lo continuamos haciendo a día de hoy. Es parte de una larga tradición, como tendremos ocasión de ver.

\section{I. Fuentes ignacianas para el apostolado intelectual}

En la vida de san Ignacio no se aprecia un interés especial por el trabajo intelectual. Su gran preocupación tras la conversión en Loyola consistió en "ayudar a las almas". Comenzó a hacerlo así desde Manresa ${ }^{4}$. Una atención que mantuvo al llegar a Tierra Santa, donde quería quedarse, pero ayudando igualmente a las personas ${ }^{5}$. Es ésta igualmente la motivación a la que alude cuando se determina a estudiar ${ }^{6}$. Irá a Barcelona a estudiar sólo con ese fin de ayudar mejor a las ánimas. A lo largo de su vida fue comprendiendo que alcanzar algún grado universitario le permitiría hablar de Dios, y que si no, esto le estaría vedado.

El peregrino recorrió las universidades de Alcalá, Salamanca y finalmente París, donde alcanzó el título de "maestro en artes". Todos los primeros compañeros lo eran. Algunos llegaron a ser teólogos brillantes, como Laínez o Salmerón. Pero no Ignacio. Lo suyo siguió siendo aquello de "ayudar a las ánimas" y garantizar para la Compañía -en especial a través de sus Constituciones- esta orientación de servicio a los demás, donde más falta hiciera.

¿De dónde surge, pues, ese deseo, ese afán de conocimiento que anima a la Compañía, a la primera y a la de nuestro tiempo? ¿ Se trata sencillamente de que coincidió que aquellos primeros hombres pertenecían a la intelectualidad de su tiempo e inculcaron ese interés por la cultura a generaciones sucesivas?

\footnotetext{
${ }^{3}$ CG 35, decreto 3, n. 39 (iii): El apostolado intelectual ha sido una característica definitoria de la Compañía de Jesús desde su mismo comienzo. Teniendo en cuenta los complejos e interrelacionados retos que los jesuitas han de afrontar en todos los sectores apostólicos, la Congregación hace un llamamiento a reforzar y renovar este apostolado como un medio privilegiado para que la Compañía pueda responder adecuadamente a la importante contribución intelectual que nos pide la lglesia.
}

${ }^{4}$ San IGnacio, Autobiografía, n. 26.

${ }^{5}$ lbid. n. 45.

${ }^{6} \mathrm{lbid}$. n. 50. 
En realidad, las fuentes de este anhelo profundo de conocimiento se encuentran en nuestro núcleo místico, en la experiencia de Ejercicios, si bien no se trata de algo obvio.

El eje medular de la tradición ignaciana se sitúa en un encuentro personal con Dios que libera, compromete y envía. Se trata de experiencia directa de lo divino ${ }^{7}$, siempre tan sorprendente, desbordante y subversiva. El Dios que protagoniza e inicia este encuentro no se halla fuera de esta realidad, sino que se sitúa en el mundo, en su sencillez y en su profundidad. Ése fue el mayor don que recibió Ignacio en la visión que tuvo junto al río Cardoner: ver a Dios en el mundo y al mundo en Dios; el mundo visto desde Dios, Dios visto desde el mundo. Una experiencia que no es sino una profundización vivencial, mística, del logro dogmático cristológico de Calcedonia.

Esto justifica que en el creyente que se nutre de esta tradición surja un ávido interés por el mundo. Para descubrir a Dios, su presencia y su acción, no hace falta huir del mundo, sino sumergirse en él ${ }^{8}$. En la perspectiva ignaciana Dios y mundo no pueden separarse. Dios nos remite al mundo y el mundo a Dios. $Y$ la actitud en la que queda sumida esta perspectiva es oblativa, no meramente contemplativa, sino de involucración en la dinámica del amor. Así el deseo de "ayuda a las almas" del peregrino terminará expresándose como "amar a Dios en todas las cosas y a todas en él"9. Nadal utilizará otra expresión, aún más conocida, "ser contemplativos en la acción". Gran parte del modo de proceder de la Compañía se explica desde esta intuición que lgnacio vivió en el Cardoner, la experiencia más determinante posiblemente de toda su biografía.

En los Ejercicios Espirituales (en adelante, EE) hay dos contemplaciones que mueven a este conocimiento del mundo: en primer lugar, la Contemplación de la Encarnación ${ }^{10}$. En ella se nos pide contemplar la redondez de la tierra, con sus gentes en situaciones tan diversas, naciendo o muriendo, riendo o llorando...

\footnotetext{
7 Para un comentario libre y sugerente de esta cuestión puede verse K. RAHNER (1990) Palabras de Ignacio de Loyola a un jesuita de hoy, Santander, Sal Terrae (Col. Aquí y Ahora 8), pp. 6-8.

${ }^{8}$ CG 34, decreto 4, n. 7: Tanto en nuestra vida personal de fe como en nuestro apostolado, nunca se plantea una disyuntiva entre Dios o el mundo: siempre se trata de Dios en el mundo, trabajando para llevarlo a su plenitud de modo que el mundo llegue finalmente a ser plenamente en Dios.

${ }^{9}$ Constituciones de la Compañía de Jesús, n. 288.

${ }^{10}$ EE $101-109$.
} 
Ignacio nos invita a descubrir en el interior de la humanidad una corriente de redención que solicita la colaboración humana: se trata del "hagamos redención" de la Trinidad que llama a la puerta de María pidiendo permiso para comenzar su obra de salvación. Al descubrir ese flujo de redención podemos distinguir su llamada a disponer nuestras personas y a participar en ese movimiento liberador. La actitud de contemplación del mundo que subyace aquí es activa, implicativa: viendo lo que hacen las personas de la Trinidad y cómo accede María a su solicitud, se nos convoca a hacer lo mismo.

En segundo lugar, tenemos la Contemplación para alcanzar amor ${ }^{11}$, donde lgnacio quiere que alcancemos "conocimiento interno de tanto bien recibido". En uno de los puntos que nos invita a considerar nos habla de un Dios que habita en los elementos, en las plantas, en los animales y en los seres humanos ${ }^{12}$. Esto va a dar pie a una actitud más contemplativa, más extática, más pasivo-receptiva.

Sin embargo, en esta misma contemplación, Ignacio habla de un Dios que labora y trabaja por mí en todas las realidades de la creación ${ }^{13}$, lo cual nuevamente nos remite a un saber que nos involucre en la acción.

En resumen, los Ejercicios nos disponen a un conocimiento del mundo, con una doble actitud, una más activa y otra más receptiva, si bien con una preeminencia de la primera sobre la segunda, como si, de algún modo, la segunda se orientara hacia la primera y estuviera a su servicio.

Pero los Ejercicios nos dan pie a otra consideración de importancia y a la que me referiré largamente más adelante. El conocimiento al que acostumbra a dirigirnos lgnacio es un "conocimiento interno". Con esta expresión parece señalar un conocimiento vivencial, experiencial, sensible, afectivo, sapiencial y sintético. Es ese el conocimiento que satisface el ánima, el que permite gustar y sentir las cosas internamente ${ }^{14}$. No se refiere tanto a un saber exhaustivo, enciclopédico, aséptico o fríamente analítico.

\footnotetext{
${ }^{11}$ EE $230-237$

${ }^{12}$ EE 235.

${ }^{13}$ EE 236.

${ }^{14}$ EE 2.
} 
Un último acento que podemos rescatar de la tradición ignaciana para el tema que nos ocupa es el magis (más). El mayor servicio exigiría aquí una seria competencia en el conocimiento, lo cual obviamente está relacionado con una investigación de profundidad y de calado.

\subsection{El apostolado intelectual en nuestra tradición histórica}

Pero no es sólo que encontramos en nuestras fuentes ignacianas resortes que nos lanzan a un mejor conocimiento del mundo. Como señalábamos antes, el apostolado intelectual ha constituido una característica esencial de la Compañía de Jesús desde sus comienzos ${ }^{15}$ : en su versión teológica-de manera que asomarnos a lo divino ayudara a esclarecer lo humano-y en su versión antropológica -de modo que la mirada sobre lo humano favoreciera comprender lo divino-.

\subsection{La investigación teológica: mirar lo divino para comprender lo humano}

Tal vez la mayor tarea investigadora en la Compañía haya consistido precisamente en la investigación teológica: un ejercicio de redecir a Dios y de acercar las cosas de Dios al ser humano. Si el encuentro con Dios ocupa el lugar esencial de la tradición jesuítica, la teología está dirigida a posibilitar y ganar relieve en ese encuentro con Dios. Mirar lo divino para comprender lo humano. Rahner se sitúa en el centro de este cometido y sus frutos se cuentan entre los aportes fundamentales de la Compañía a la teología de la Iglesia. Lo llamativo es que su aporte es típicamente ignaciano. Como dirá Sesboüé: ...el pensamiento más especulativo de Karl Rahner es la tematización teológica de la experiencia espiritual del encuentro con Dios tal como lo propone lgnacio ${ }^{16}$.

Con frecuencia, se trata de una teología preparada para releer las realidades humanas desde la vida de Dios. Una teología de las realidades del mundo y por eso con frecuencia de frontera. No fríamente especulativa, sino vital, que procura la "ayuda de las ánimas", que tiende puentes con la cultura de su tiempo. No es raro que esa teología sea la mayor parte de las veces de vanguardia, ni que por eso mismo haya suscitado tantos debates a lo largo de la historia.

\footnotetext{
${ }^{15}$ También la CG 34 lo mencionaba, en el decreto 16, n. 1: La Compañía ha tenido en gran estima la labor intelectual, como significativa aportación a la obra creadora de Dios y al reconocimiento de la legítima autonomía de la actividad humana.
}

${ }^{16}$ B. SESBOÜÉ, "Espiritualidad ignaciana y teología": Revista CIS 115 (2007) 33. 
Tampoco es extraño que de forma reiterada las dificultades se localicen en la cristología, pues es el área de la teología que intenta precisar la relación entre lo divino y lo humano. Esa relación, resuelta dogmáticamente en Calcedonia, está llena de consecuencias para la articulación entre lo religioso y lo político; entre la jerarquía y el pueblo de Dios; entre lo sagrado y lo profano; para la relación con las religiones... y de su aclaración renovada en cada momento de la historia surgen muchas soluciones creativas y también numerosos conflictos. Tal vez este sea el gran tesoro del cristianismo, curiosamente nunca apresado del todo y en búsqueda continua de nuevas síntesis.

La teología de la que aquí hablamos es aquella preocupada por las consecuencias que "lo de Dios" tiene para la vida de las personas, y no tanto aquella especulativa y centrada exclusivamente en contemplar el misterio divino, y embelesada en él, más olvidada de lo que entonces suceda con los seres humanos.

Esta teología engarza preferentemente con la Contemplación de la Encarnación, en la que el misterio divino se introduce en nuestra historia para salvarla. Es en el discurrir de nuestra historia concreta, en los acontecimientos de la vida, donde podemos descubrir los signos de la palabra trinitaria que a día de hoy sigue diciendo "hagamos redención".

\subsubsection{Investigación científica y cultural: mirar lo humano para descubrir lo divino}

Desde los primeros tiempos hubo jesuitas notables que se esforzaron por aclarar aspectos de la realidad desde un punto de vista científico. Escrutando el universo desvelaban a Dios. Contemplaban la naturaleza como texto que nos habla del Creador. En ocasiones su interés científico estaba primariamente al servicio de otros fines, como pueda ser el caso de Ricci en la China. Su cultivo de la ciencia pretendía ganar una credibilidad ante el emperador que le habilitara para anunciar su ciencia divina. Pero con frecuencia la contribución de los científicos jesuitas ha consistido en no permitir que la ciencia hablara sólo desde voces agnósticas. En ese sentido, muchos de ellos nos han ayudado a comprender que la ciencia y la fe no luchan en competencia por un mismo espacio, sino que se complementan y enriquecen mutuamente. Estos hombres han tendido puentes entre la ciencia y la fe. Su tarea -junto a la de otros muchos cristianos- ha sido crucial para que hoy podamos ser ciudadanos modernos, al tiempo que creyentes. Nos han permitido comprender que el conocimiento científico no pone en jaque nuestra fe, sino que en muchos casos la profundiza y madura. A otros científicos agnósticos les ha obligado a cuestionar las supuestas bases ateas de 
la ciencia, que no son tales, sino que como en otros campos, la hipótesis Dios es sencillamente innecesaria para la evolución de la investigación científica. Ante la pregunta sobre Dios, el científico, en su condición de científico, sencillamente se encoge de hombros, desconoce sobre qué se le pregunta.

Es probable que en nuestros días la presencia de los jesuitas científicos sea decreciente. Se han multiplicado los ámbitos del saber, el conocimiento se ha compartimentado exponencialmente, no es fácil identificar cuáles sean en cada momento los centros de interés fundamentales y no es factible virar la carrera científica a cada rato...

A mi entender, más relevante en la historia de la Compañía que este campo de la ciencia, es el de los estudios culturales. Ha habido muchos jesuitas que, enamorados de Dios, quedaron prendados de lo humano en culturas muy distintas ${ }^{17}$. No se trataba de grandes académicos, sino de hombres apasionados por la gente, aunque su contribución a la academia haya sido muy importante. El ser humano en su diversidad, riqueza, sencillez, hondura, fragilidad, sabiduría, les hablaba con nuevos trazos del Dios que buscaban con desvelo. Descubrieron en las personas con las que se encontraban al Espíritu de Dios que, desde la noche de los tiempos, habitaba en ellas. Y amando y desentrañando aquellas culturas, adoraron al Dios que habita en todo. De ahí las gramáticas, alfabetos, estudios etnográficos... Los ejemplos son numerosísimos y muestran cómo los jesuitas creyeron de verdad que "Dios habita en las criaturas"18. Coexistiendo con otras muchas tendencias presentes en la Iglesia que suponían que la fe debía propagarse inseparablemente unida a una cultura dominante, ellos se sintieron interpelados por las culturas que encontraron a su paso, en las que descubrieron que latía el Espíritu. Hoy esa tradición continúa presente. El decreto sobre Nuestra misión y la cultura de la CG34, así como nuestra implicación con los pueblos indígenas, muy extendida geográficamente, son algunas de las expresiones de ello.

En resumen, podríamos afirmar que el apostolado intelectual de la Compañía, ya sea en su versión teológica, ya en su versión científica, ha estado orientado a tender puentes entre Dios y el ser humano.

\footnotetext{
${ }_{17}$ CG 34, decreto 4, n. 10: Esta intuición es la que ha llevado a muchos jesuitas a adoptar una actitud positiva hacia las religiones y culturas con las que trabajan... Esto los impulsó (a los primeros jesuitas) a profesar un profundo respeto por las culturas indígenas, a componer diccionarios y gramáticas de lenguas autóctonas y a ser pioneros en el estudio de los pueblos con los que trabajaban y a los que trataban de comprender.
}

${ }^{18}$ Contemplación para alcanzar amor, EE 235. 


\section{Nuestra misión hoy demanda investigación social}

Una vez visto que nuestra propia tradición ignaciana y jesuítica han demandado -y lo siguen haciendo hoy- un serio trabajo intelectual e investigador, habría que ir un poco más allá: la misión fe-justicia, tal como fue formulada en la CG32 en 1975 y confirmada con aspectos renovadores en las siguientes tres Congregaciones Generales, exige de forma aún más imperiosa un sólido apostolado intelectual más orientado hacia la investigación social.

\section{I. Nuestra misión fe - justicia}

Cuando en 1975 se llega a formular nuestra misión en clave de defensa de la fe y promoción de la justicia, se tiene muy presente que el mundo en el que nos hallamos se debate en una lucha dialéctica entre los afanes de liberación y poderosas dinámicas de exclusión ${ }^{19}$. De ahí que se hable precisamente de "promoción". Se precisa un compromiso activo, deliberado y sostenido contra las fuerzas que generan explotación ${ }^{20}$. Estamos en una lucha.

Reconozco que a muchas personas que pueden tener una posición vital más conciliadora, se les hace muy difícil aceptar que nos encontramos en lucha. Pero cuando experimentamos de cerca la violencia, las vejaciones a las personas, las injusticias cotidianas, la parcialidad de la ley, la organización de la propie-

${ }^{19}$ CG 32, decreto 4, n.6: nuestro mundo... está, sin embargo, dividido por la injusticia -injusticia no sólo de las personas, sino encarnada también en las instituciones y las estructuras socio-económicas, que dominan la vida de las naciones y de la comunidad internacional. CG 32, decreto 4, n. 27: El hombre puede hoy día hacer el mundo más justo, pero no lo quiere de verdad. Su nuevo señorío sobre el mundo y sobre él mismo sirve frecuentemente más, de hecho, para la explotación de los individuos y las colectividades y los pueblos que para un reparto equitativo de los recursos del planeta; desencadena más rupturas y divisiones que comunión y comunicación; más opresión y dominación que respeto de los derechos individuales y colectivos en una real fraternidad.

20 P. H. KolvenBACH (1991) Selección de escritos 1983-1990, "Discurso a los Directores de Centros Sociales", (Roma, 16 de mayo de 1987), Madrid, Provincia de España, p. 506: Debemos, por tanto, mantener el término 'promoción de la justicia', no tanto por la intelección de su contenido como por la expresión de un dinamismo que se origina en el Nuevo Testamento y lleva a una acción concreta que participa en la lucha por la justicia y que contribuye a reemplazar las estructuras injustas por la justicia. La utilización del término 'justicia' no nos permite desviar nuestra atención de los problemas bien concretos y reales; la justicia nos empuja a confrontar la dura realidad en la que a la persona se le quita lo que debe tener para llegar a ser totalmente humana. 
dad... sólo podemos reconocer que aquí hay una violenta colisión de intereses irreconciliables ${ }^{21}$.

Esta misión implica un posicionamiento previo. Estamos de parte de los pobres, en complicidad con ellos. No se puede separar esta misión de la opción preferencial por los pobres, es interior a esta opción ${ }^{22}$. Lo cual supone una crítica a muchas alianzas afectivas clásicas, como bien sabía Arrupe, pues estar con los pobres supondrá distanciarnos de aquellos que sencillamente "pasan" de ellos.

Esta visión, que posiblemente se hallaba muy extendida en los años 1970, se ha puesto hoy en entredicho. El mundo se nos hizo más complejo y con ello más opaco. Las fuerzas que oprimen nuestro mundo se han ocultado a nuestra vista. Resulta casi imposible dilucidar responsabilidades. De esta manera la injusticia queda camuflada, ya no parece responder a una trama articulada por poder humano alguno, sino que se nos antoja una fatalidad irreducible, un rasgo que podríamos decir "connatural" a nuestro mundo, perteneciente a la naturaleza arbitraria de las cosas. Sin embargo, la realidad nos sigue diciendo que son muchas las personas y los grupos que resultan beneficiados por este supuesto "orden" del mundo y que se esfuerzan por mantenerlo, redundando a su vez en la pobreza y desigualdad de la mayoría.

Por este motivo, esta perspectiva dialéctica se hace cada vez más difícil de sostener en el ámbito público e incluso en ámbitos jesuíticos, a pesar de que queda avalada por la normatividad del Evangelio y la lucidez de la contemplación de las dos banderas.

Por otro lado, la opción por la justicia nos exige muchas cosas: posicionamientos públicos, utilización adecuada de los medios de comunicación, cuentas claras,

${ }^{21}$ ¿Aceptamos el hecho de que los recursos del mundo deberían beneficiar a todos y que es tan igualmente inmoral que unas naciones se apropien para sí la mayor parte de estos bienes, dejando a la mayor parte en la pobreza, como que, dentro de una nación, unos pocos vivan en el lujo, mientras la masa se ve en necesidad? ¿Aceptamos que los pobres y hambrientos de la tierra tienen derecho en justicia a una justa participación en su riqueza? ¿Aceptamos que hay algo desordenado en un sistema de mercado que hace que los recursos disponibles sean antes para los que los pueden pagar, que para los que los necesitan? ¿Aceptamos que un orden económico que, en lugar de encaminarse a satisfacer necesidades de todos, favorece el super-consumo de los ya ricos, es un orden que ha de ser cambiado?: P. ARrupe, Discurso en el Congreso Eucarístico, 1 de agosto de 1976.

${ }^{22}$ En realidad, y de acuerdo con Benedicto XVI, la opción preferencial por los pobres está implícita en la fe cristológica en aquel Dios que se ha hecho pobre por nosotros para enriquecernos con su pobreza (2 Cor 8, 9): cf. Alocución a la CG35 (21 de febrero de 2008), citando el discurso pronunciado en la Conferencia General del Episcopado Latinoamericano celebrada en Aparecida (Brasil) en 2007. 
interlocuciones políticas e institucionales, mucha capacidad de innovación. Esta opción requiere respuestas apostólicas más complejas, implica un magis. Es decir, la promoción de la justicia nos demanda elevar nuestros perfiles apostólicos, lo cual ha de llevar consigo una renovación integral de nuestros ministerios para que se adecuen a esta misión ${ }^{23}$.

Es esta necesidad de elevar nuestro perfil apostólico, de manera que nuestros ministerios estén orientados a anunciar una fe que obra la justicia y operar una justicia que brota de la fe, la que nos exige un más adecuado conocimiento de nuestro mundo y, en consecuencia, un más agudo análisis social.

\subsection{En tiempos de globalización compleja}

La globalización ha agudizado la necesidad de este conocimiento del mundo y esta investigación social. La complejidad del mundo y la interrelación entre los aspectos cultural, político, económico, religioso... están creciendo aceleradamente. Esto mueve a muchos sectores sociales beneficiarios netos de esta realidad a un desinterés por las cuestiones globales y a un atrincheramiento en espacios de intereses confinados, sean virtuales o estén ligados a lo local. De ahí la proliferación de todo tipo de fundamentalismos e integrismos. Más vale un mal refugio que exponerse a la fría intemperie del globo. El mundo hoy produce vértigo.

Sin embargo, somos conscientes de que es la organización de este mundo la que está generando "estructuras de pecado" 24 y sometiendo a la exclusión y explotación a millones de personas en el mundo. En consecuencia, nosotros no nos podemos desentender de él, sino que la fidelidad a nuestra misión nos exige desentrañarlo.

Los jesuitas creemos conocer bien esta realidad de nuestro planeta. Pero no es así. El globo está envuelto en un cambio permanente que nos sorprende cada día. Los cambios son vertiginosos y exigen atención continua: ¿quién iba a decir en los años 1980 que seríamos la octava potencia económica del mundo? $\dot{\partial}^{Y}$ que en sólo unas pocas semanas pasaríamos de ser la economía más pujante de Europa a la más amenazada? ¿ $\bigcirc$ que los inmigrantes cambiarían definitiva-

\footnotetext{
${ }^{23}$ CG 32 , decreto 4, nn. 9 y 76.

${ }^{24}$ Juan Pablo II (1987), Sollicitudo Rei Socialis, n. 36.
} 
mente el rostro de nuestra sociedad en el curso de una década? ¿Quién podía imaginarse que la secularización avanzaría a tal velocidad? ¿Quién previó que el muro caería como un castillo de naipes y tras ese desmoronamiento se transformaría el conjunto del panorama mundial? ¿ Nos habríamos atrevido a pensar que el $25 \%$ de los niños nacerían en el día de hoy de madres legalmente solteras? $\dot{¿}^{O}$ que las familias podrían dejar de ser sencillamente parejas heterosexuales con sus hijos?...

Es en este mundo donde seguimos queriendo estar. Mundo en Dios, mundo de Dios. Si no lo conocemos mejor, nuestra misión perderá incidencia.

\section{Precisamos síntesis sapienciales que orienten y motiven}

Hemos de partir del reconocimiento de que la investigación social está abierta a la orientación apostólica, en particular cuando desvela los aspectos creativos y esperanzadores de la realidad, cuando denuncia las fuerzas que disgregan o excluyen, cuando propone nuevos modos de abordar las problemáticas sociales... En el fondo, cuando pretende ser agente de transformación e incidir en el ámbito público ${ }^{25}$.

Una vez dicho esto, también debemos afirmar que necesitamos algo más que sólo investigación social. Es preciso ubicarla en un panorama más amplio. Ignacio viene en nuestra ayuda: siguiendo su estela, precisamos más conocimiento interno que exhaustividad, más saber sintético que analítico, más implicación afectiva que desasimiento aséptico, más interdisciplinariedad que fragmentación ${ }^{26}$ y dosis muy importantes de discernimiento ${ }^{27}$. Tenemos necesidad de síntesis

\footnotetext{
${ }^{25}$ No creo que el conocimiento y la investigación, en sí mismos, sean apostólicos. Pero son imprescindibles para cualquier actividad u orientación apostólicas. El conocimiento puede enfocarse de muchas maneras. Se necesita ciencia base, pero el fin apostólico se alcanza por un determinado enfoque de los contenidos de esa ciencia base.

${ }^{26}$ CG 34, decreto 17, n. 10: Nuestras universidades deben promover el trabajo interdisciplinar... De este modo, sirviendo a la fe y promoviendo la justicia en línea propiamente universitaria, podrán descubrir nuevos horizontes y nuevos campos de investigación, enseñanza y extensión universitaria, contribuyendo así a la transformación de la sociedad en busca de niveles más profundos de justicia y libertad.
}

${ }^{27}$ CG 32, decreto 4, n. 10: Esto [la adaptación de nuestros ministerios e instituciones] exige discernimiento... Hemos de aplicarlo, igualmente, para conocer más profundamente movimientos, aspiraciones y combates que agitan a nuestros contemporáneos: cuanto conmueve el corazón de la Humanidad. 
sapienciales ${ }^{28}$ que den cuenta de nuestro mundo, que nos permitan hacernos cargo de él para encargarnos de él ${ }^{29}$. Síntesis realizadas desde una mirada compasiva y teologal ${ }^{30}$. Esas síntesis tienen que ver con aquel "conocimiento interno" que Ignacio nos solicita demandar en la Contemplación de las dos banderas: conocimiento interno de los engaños del mal caudillo, y ayuda para dellos me guardar; y conocimiento de la vida verdadera que muestra el sumo y verdadero capitán, y gracia para le imitar ${ }^{31}$. Unas síntesis que nos proporcionen conocimiento interno, lucidez ante la realidad, para descubrir en ella las dinámicas de exclusión, extorsión y muerte, a fin de que las confrontemos; y para celebrar las corrientes de vida y liberación a fin de que nos comprometamos con ellas. Hablamos, por tanto, de síntesis sapienciales o conocimiento interno o ignaciano de la realidad, comoquiera que deseemos llamarlo, pues a mi entender, no contamos con un vocablo acuñado que designe esta realidad de la que estamos hablando.

La investigación social se debe situar al servicio de estas síntesis. Esto no quiere decir que sea innecesaria, al contrario, es más necesaria que nunca. Un día un jesuita decía: "necesitamos discernimiento y no análisis". Otro rápidamente le respondió: "sin análisis no hay discernimiento" 32 . Pues cuando no hay análisis

28 P. H. KolvenBACH (2007) Selección de escritos (1991-2007), "Conferencia en la Universidad de Santa Clara" (6 de octubre de 2000), Madrid, Provincia de España, p. 305: ...lo que está en juego es... un diálogo interdisciplinar sostenido de investigación y reflexión, un continuo poner en común los conocimientos de todos. Su intención es asimilar las experiencias y las intuiciones de las diferentes disciplinas en 'una visión del conocimiento que, muy consciente de sus limitaciones, no se satisfaga con los fragmentos, sino que intente integrarlos dentro de una síntesis sabia y verdadera' de la realidad de nuestro mundo. Desgraciadamente muchos profesores no se sienten todavía, académica, humana y, me atrevería a decir, espiritualmente, preparados para un intercambio de tal envergadura.

${ }^{29}$ A esto se refiere la CG 34 en su decreto 16, n. 7 cuando dice: La reflexión teológica, el análisis social y el discernimiento son fases de un proceso que el Papa Juan XXXIII y el Concilio Vaticano II Ilamaban 'lectura de los signos de los tiempos'... Su objetivo es discernir, aclarar e interpretar las oportunidades y problemas de la vida contemporánea.

${ }^{30}$ CG 34, decreto 16, n. 8: Esta reflexión... será tanto más fecunda cuanto más se arraigue en la experiencia de una fe personal, vivida y expresada en la comunidad cristiana. Debe estar atenta a las cuestiones que plantea la realidad al creyente. Y el jesuita dedicado a esta reflexión debe saber juntar estos cuestionamientos concretos con la escucha directa de la voz de Dios en su oración personal.

\section{${ }^{31}$ EE 139.}

${ }^{32}$ CG 34, decreto 26, n. 20: En el contexto de los complejos retos y oportunidades de nuestro mundo contemporáneo, nuestro ministerio requiere toda la erudición e inteligencia, imaginación y perspica- 
hay invención, proyección pura. Simplemente vemos lo que queremos. El conocimiento sapiencial debe ser riguroso. Ese es el papel que el análisis social debe desempeñar: aportar rigor, honestidad con lo real.

Estas síntesis que elaboren un conocimiento profundo de la realidad deberán:

- Contar con un rigor atento a una multiplicidad de perspectivas, y para ello,

1) estarán basadas sobre datos e investigaciones sólidas ${ }^{33}$;

2) integrando en su análisis una multiplicidad de disciplinas ${ }^{34}$.

- Ser realizadas en clima de discernimiento orante en común, y para ello,

3) desvelando nuestros intereses ocultos y alianzas afectivas;

4) serán elaboradas desde la experiencia: en contacto con los pobres y con

cia, estudios sólidos y análisis rigurosos que podamos acumular. CG 32, decreto 4, n. 44: En ningún caso podemos dispensarnos de un análisis -lo más riguroso posible- de la situación desde el punto de vista social y político. A ese análisis es preciso aplicar las ciencias tanto sagradas como profanas y las diversas disciplinas especulativas o prácticas, y todo esto requiere estudios profundos y especializados. Nada puede dispensarnos, tampoco de un discernimiento serio desde el punto de vista pastoral y apostólico. De aquí han de brotar compromisos que la experiencia misma nos enseñará cómo llevar más adelante. CG 32, decreto 4, n. 60: (Esta misión nos debe llevar) a dar más amplitud a la investigación y a la reflexión teológica realizadas de manera interdisciplinar e integradas en las diversas culturas y tradiciones, para esclarecer los grandes problemas a los que la lglesia y la Humanidad deben hoy hacer frente.

33 P. H. KolvenBACH (1991) Selección de escritos 1983-1990, citado "Alocución a la Congregación de Procuradores, sobre el estado de la Compañía" (Roma, 3 de septiembre de 1987), p. 197: Es, efectivamente, toda la actividad apostólica de la Compañía la que, por un mayor servicio, debería penetrarse de rigor intelectual y su preparación debería estar asegurada en profundidad por estudios y de renovación; nuestro esfuerzo, en fin, debería desembocar en una contribución valiosa al servicio del pueblo de Dios en este mundo, sacrificando nuestras inclinaciones espontáneas hacia lo inmediato y lo espectacular y nuestras preferencias personales de un activismo poco reflexionado y de un ambiente social estimulante en favor del silencio austero, destinado a fundamentar la calidad apostólica de toda actividad.

${ }^{34}$ P. H. KolvenBACH (1991) Selección de escritos 1983-1990, citado "Discurso a la Universidad lberoamericana sobre un nuevo modelo de Universidad" (México, 23 de agosto de 1990), p. 413: Los desafíos a los que se ven abocados los hombres y mujeres en este umbral del s. XXI no son fáciles. Una sola disciplina académica no puede pretender ofrecer una solución comprehensiva a problemas como la investigación genética, la deuda internacional, los derechos humanos... Y en p. 414: Estos problemas no se solucionan en una forma unidisciplinar, pues abarcan valores humanos y no simplemente técnicos. 
aquellas personas e instituciones sociales que trabajan en favor de ellos ${ }^{35}$;

5) dejándose afectar por la realidad;

6) incorporando una lectura teológica ${ }^{36}$.

- Incluir una orientación práctica que vehicule el compromiso y la implicación:

7) generando planteamientos y propuestas;

8) elaborando modos de divulgación razonada y creíble que nos ayuden a todos en la formación permanente, alimenten nuestras motivaciones profundas $y$ afectos $y$ alienten nuestra fe;

9) catalizando una incidencia pública, al establecer una agenda de interlocución con agentes sociales, eclesiales y políticos.

35 P. H. KolvenBACH (2007) Selección de escritos (1991-2007), citado "Conferencia en la Universidad de Santa Clara" (6 de octubre de 2000), p. 306: Para asegurar que las necesidades reales de los pobres encuentran su sitio en la investigación, los profesores precisan de una colaboración orgánica con aquellos que, en la lglesia y en la sociedad, trabajan entre los pobres y en favor de ellos, buscando activamente la justicia. Deberían implicarse con ellos en todos los aspectos: presencia entre los pobres, diseño de la investigación, recogida de datos, profundización en los problemas, planificación y acción, ejecución de la evaluación y reflexión teológica. En cada Provincia de la Compañía donde existen universidades nuestras, habría que dar prioridad a las relaciones de trabajo del profesorado con los proyectos del apostolado social jesuita... E igualmente en p. 307: Cuando los profesores optan por el diálogo interdisciplinar y por la investigación socialmente comprometida en colaboración con las plataformas del apostolado social, están ejemplificando y modelando un tipo de conocimiento que es servicio. $Y$ eso es lo que aprenden los estudiantes imitándolos en cuanto 'maestros de vida y de compromiso moral', como dijo el Santo Padre.

${ }^{36}$ Normas Complementarias de las Constituciones de la Compañía de Jesús, n. 294: Entre todas las modalidades de dedicación al apostolado intelectual... la investigación y la reflexión teológicas ocupan un puesto primordial... tienen un valor singular para discernir, aclarar e interpretar las oportunidades y problemas de la vida contemporánea... P. H. KolveNBACH (2007) Selección de escritos (1991-2007), citado "Alocución en la Universidad Javeriana en la inauguración de la nueva sede de la Facultad de Teología" (Bogotá, 29 de octubre de 2001), p. 329: La Teología necesita de las otras ciencias, lo mismo que éstas necesitan de la Teología... para entablar un diálogo más estrecho con todas las otras disciplinas. En un mundo cada vez más atomizado y especializado, la integración del saber es uno de los deberes ineludibles de una Universidad digna de ese nombre... De este modo se podrán abrir nuevos horizontes a la docencia y a la investigación, contribuyendo así a la constante superación de la calidad académica y a la misma transformación de la sociedad. Y también en p. 336: Si su Teología y su quehacer universitario quieren tener un sentido, dejen que la realidad perturbadora que les rodea penetre en este campus, para reflexionar sobre ella y darle la respuesta que la lglesia y el país tienen derecho a esperar de ustedes como Universidad. J. B. LIBANIO (2007) "El proyecto de Dios y su encarnación en la historia", Revista CIS 115 (2007) 39: Ya ha pasado el tiempo del reinado solitario de la teología. La Compañía reúne las condiciones para promover un intenso trabajo disciplinar en el que la teología participa con su colaboración específica. 
En general, podemos afirmar que carecemos de -o no contamos con suficientessujetos colectivos, o comunidades de discernimiento, capaces de llevar a cabo este trabajo. Para ello precisaremos de metodologías nuevas ${ }^{37}$ y de maestros que orienten este trabajo ${ }^{38}$. Es decir, hay mucho por hacer.

A mi modo de ver, éste es el gran reto en el área del conocimiento social. Trato de resumir el camino seguido hasta aquí: aspiramos a responder mejor a nuestra misión fe y justicia, ése es el foco de nuestro interés. Para lograrlo necesitamos un conocimiento profundo de la realidad, que lgnacio calificaría de "interno". Este conocimiento interno precisa de una diversidad de elementos, uno de los cuales es la investigación social. Se trata de un elemento crucial, porque sin él careceremos de rigor, pero se trata de uno más junto a otros.

Si la investigación encuentra su ubicación adecuada al servicio de nuestra misión, esto llevará consigo que debe reunir algunas características. En primer lugar, necesitará focalizarse en algunos campos sociales, en aquellos que son más relevantes hoy para el desarrollo de nuestra misión ${ }^{39}$. Otros campos podrán ser también de interés, pero los límites de nuestros recursos y las demandas de la misión obligarán a dejarlos a un lado. En segundo lugar, esta investigación

${ }^{37}$ Cf. SeCRETARIADO para la JusticIA SOCiAl de LA Compañía de Jesús (2006) Globalización y marginalización, Roma, febrero de 2006, nn. 83-87. Estos números muestran la necesidad de ampliar una visión reducida del conocimiento, por otra como "conocimiento de conocimientos", es decir, la necesidad de evaluar el conocimiento mismo y sus procesos. De acuerdo con este documento se requiere un cambio de paradigma y de metodología: una actividad multi-, inter- y trans-disciplinar que pueda realizarse en equipos, donde se elaboren nuevos tipos de conocimiento, con métodos y herramientas alternativas. Habría de utilizarse también pensamiento lateral, experiencias y formas simbólicas. Para ello se precisaría una articulación más estrecha entre actividades clave, como experiencias de campo, reflexión/análisis y advocacy.

${ }^{38}$ L. CARUANA (2007) "Filosofía, experiencia y vida espiritual", Revista CIS 115 (2007) 54, citando a Arrupe: El remedio contra esta fragmentación consiste en crear una nueva categoría de investigadores, cuya tarea es ofrecer una síntesis, mediante el desarrollo de la creatividad y comprensión disciplinar.

39 P. H. KolveNBACH (2007) Selección de escritos (1991-2007), citado "Alocución en la Reunión Internacional sobre la Educación Superior de la Compañía de Jesús" (Monte Cucco, 27 de mayo de 2001), p. 318: La universidad debe ser el lugar donde se airean cuestiones fundamentales que tocan a la persona y a la comunidad humana, en el plano de la economía, la política, la cultura, la ciencia, la teología, la búsqueda de sentido. La universidad debe ser portadora de valores humanos y éticos, debe ser conciencia crítica de la sociedad, debe iluminar con su reflexión a quienes se enfrentan a la problemática de la sociedad moderna o postmoderna, debe ser el crisol donde se debatan con profundidad las diversas tendencias del pensamiento humano y se propongan soluciones. 
social deberá preguntarse en favor de quién y en favor de qué está ${ }^{40}$. En tercer lugar, y puesto que en todos los campos no podremos contar con personas preparadas debido a la creciente diversidad de acercamientos del saber, se necesitarán las aportaciones de otros muchos investigadores, pertenezcan o no a nuestras instituciones.

Los centros sociales también deberán jugar su papel en la elaboración de este conocimiento interno de la realidad social ${ }^{41}$. Si las síntesis requieren discernimiento, éste se lleva a cabo de modo más adecuado cuando estamos en movimiento y en cercanía a la realidad. Por eso las instituciones en contacto con las realidades sufrientes del mundo tendrán mucho que decirnos.

${ }^{40}$ P. H. KolvenBACH (2007) Selección de escritos (1991-2007), citado "Conferencia en la Universidad de Santa Clara" (6 de octubre de 2000), p. 305: ...todo el conocimiento que se adquiere en la universidad es valioso en sí mismo, pero es además un conocimiento que tiene que preguntarse a sí mismo, 'en favor de quién y en favor de qué' está. E igualmente en la p. 306: Ningún punto de vista es neutro o prescinde de los valores. En nuestro caso de jesuitas, el punto de vista, por preferencia y por opción, es el de los pobres. Por eso el compromiso de nuestros profesores con la fe y la justicia conlleva un desplazamiento significativo del punto de vista y de los valores elegidos. Al adoptar la perspectiva de las víctimas de la injusticia, nuestros enseñantes buscan la verdad y comparten esa búsqueda y sus resultados con nuestros estudiantes. Una pregunta legítima para cada uno de los profesores, aunque no resulte académica, sería: 'cuando investigo y enseño, ¿̇dónde y con quién está mi corazón?'. O también en p. 318: Si bien la educación superior, como instrumento y como medio, tiene un valor intrínseco, cabe siempre preguntarse 'para quién' y 'para qué'. La respuesta a estas preguntas estará siempre estrechamente ligada al bien común y al progreso de la sociedad humana.

${ }^{41}$ P. H. KolveNBACH (1991) Selección de escritos 1983-1990, citado "Alocución a la Asamblea de Enseñanza Superior de la Compañía en Estados Unidos, sobre las características en nuestra educación" (Georgetown, 7 de junio de 1989), p. 391: La misión que hoy han de abordar las Universidades de los jesuitas es tan compleja que no podéis, sin más, tener la seguridad de llevarla a cabo por vosotros mismos. Por ello es de la mayor importancia el que, de una forma o de otra, los que estáis dedicados al apostolado de la enseñanza en la Compañía toméis la iniciativa de colaborar con los jesuitas que trabajan a plena dedicación en la promoción directa de la justicia... La competencia que exige el ministerio pastoral o social, que supone conocimientos extensos y profundos siempre mantenidos al día, sólo puede lograrse mediante serios y disciplinados estudios universitarios. Por ello está claro que los jesuitas destinados a este apostolado necesitan la Universidad. Cfr. Promotio lustitiae 80 (2003) n. 59: En el caso de las instituciones universitarias es de especial importancia llegar a colaborar con ellas en la determinación de líneas de investigación y formación que incidan en aspectos claves de la vida social desde la perspectiva de los pobres. Sin esa aportación específica por parte de los centros universitarios, el Sector Social no tendrá la capacidad de realizar un análisis social suficientemente profundo. Sin la conexión con el Sector Social, las universidades se separan cada vez más de los intereses de los pobres para responder fundamentalmente a las necesidades de los poderes políticos y económicos. La colaboración estrecha entre el Apostolado Social y nuestras Universidades ayudará a una búsqueda común de las raíces de nuestra identidad apostólica en 'un servicio de la fe y de las radicales consecuencias de la fe en un mundo en que se está haciendo más fácil conformarse con algo menos que la fe y que la justicia'. 
Ahora bien, ¿̇basta con las síntesis? No, pues éstas están encaminadas a orientar mejor nuestra respuesta a la misión ${ }^{42}$.

\section{Al servicio del liderazgo apostólico}

\section{I. Sólo un conocimiento interno de la realidad puede orientar nuestro liderazgo}

Cuando carecemos de ese conocimiento interno, afectivo y discernido, del que surgen llamadas apostólicas, sólo hay gestión con sentido común. No hay asunción de riesgos, hay conservación; no hay fidelidad ni creatividad, más bien reproducción degenerativa; no hay identidad, sino dilución; y me atrevería a decir que no hay futuro, sino ante todo angustia. Porque síntesis como éstas iluminarán la realidad, motivarán nuestro compromiso y orientarán la acción.

Habitualmente hay muchos conocimientos en nuestras instituciones sobre el espacio económico y legal en el que se desenvuelven y pueden estar tentadas de pensar que con eso es suficiente. Conocen bien lo que en jerga empresarial se denomina "el negocio". Sin embargo, la misión a la que responden va mucho más allá de él: un colegio no trabaja meramente para educar, eso ya lo hace la educación pública, con más medios y al menos tan bien como nosotros. Un colegio de la Compañía trata de formar personas que deseen un mundo más justo, capaces de comprometerse en comunidades en este empeño, dispuestas a sacrificios si son necesarios, que saben que la fe es un magnífico resorte de liberación integral del ser humano, para que algunas personas puedan descubrir esta fe como la fuente de sus vidas. Esa misión, como puede verse, pasa por el "negocio" de la educación, pero va mucho más allá del mismo. Sucede otro tanto con la universidad jesuítica, cuyo servicio académico debe estar al servicio de un mundo más parecido al del Reino ${ }^{43}$. $O$ con las $O N G$, que deberán

\footnotetext{
${ }^{42}$ Señala Adolfo Chércoles que el conocimiento interno no pretende un mero entusiasmo emotivo, sino transformar la sensibilidad y conducirnos a una praxis estabilizada y asegurada, en J. GARCíA DE CASTRO, director (2007) Diccionario de espiritualidad ignaciana, Bilbao - Santander, Mensajero - Sal Terrae, voz "Conocimiento interno", pp. 400-408.
}

${ }^{43}$ P. H. KolvenBACH (1991) Selección de escritos 1983-1990, citado "Alocución a la Asamblea de Enseñanza Superior de la Compañía en Estados Unidos, sobre las características en nuestra educación" (Georgetown, 7 de junio de 1989) p. 393: El servicio de la fe y la promoción de la justicia son el 
manifestar una nítida confesionalidad y sustentar comunidades cristianas que trabajan integralmente por la fe y la justicia. En la actualidad resulta crucial que todas nuestras instituciones respondan a la misión fe-justicia, porque en ello nos jugamos que en realidad sean instituciones jesuíticas ${ }^{44}$. Pero al mismo tiempo, es muy difícil. En la mayor parte de los casos, nuestras instituciones no cuentan con los recursos necesarios para llevar adelante esta labor de manera consistente.

Porque esto significa que hoy los colegios deberían saber mucho sobre inmigración, integración, identidades cruzadas, sobre procesos de integración de la segunda generación; sobre globalización, sobre política mundial, sobre ciudadanía (porque educan para que una nueva generación se haga responsable del mundo); sobre secularización, sobre socialización religiosa; sobre el papel que los medios y los estímulos tienen en la socialización primaria; sobre los modelos actuales de familia, las situaciones a las que obedecen; sobre diversidad... Las ONG deberían saber mucho más sobre los aspectos simbólicos y espirituales del desarrollo, sobre el ser humano y las culturas, sobre la relación entre religión y política, sobre fortalecimiento y liderazgo comunitario, formas alternativas de desarrollo económico, descentralización, políticas públicas, ecología y tecnología... Y así podríamos seguir repasando otros campos apostólicos.

En definitiva, un conocimiento interno de nuestra realidad social, por limitado y pobre que pueda resultar, contribuirá en una medida importante a que nuestras instituciones puedan responder mejor a nuestra misión. En un momento como el actual, de tanta precariedad de jesuitas, si instituciones como las que regenta hoy la Compañía -grandes, dinámicas y creativas- no reciben esta ayuda, se abrirán su propio camino en la actividad que desarrollan. Pero a la larga, no las podremos reconocer como jesuíticas. Tal vez nos sentiremos orgullosos de

foco mayor del apostolado de la Compañía... Estoy persuadido de que esta misión realmente no se cumplirá si el sector de la educación no tiene en ella una fe profunda. Y por ello urge que esta misión, hondamente vinculada con nuestro amor preferencial a los pobres, sea operativa en vuestras vidas y en vuestras instituciones. Debe ocupar el primer lugar de la lista.

${ }^{44}$ En la CG 34, decreto 13, n. 11 se señala que una obra de la Compañía es aquella que contribuye sustancialmente a llevar a cabo la misión de ésta, manifiesta los valores ignacianos y se denomina 'jesuítica' con aprobación de la misma Compañía. La CG 35, en su decreto 6, n. 10 se ha expresado de un modo semejante: Una obra ignaciana se puede llamar jesuítica cuando tiene una clara y definitiva relación con la Compañía de Jesús y cuando su misión concuerda con la de la Compañía, por un compromiso con la fe que realiza la justicia a través del diálogo interreligioso y una responsabilidad creativa con la cultura. 
ellas, porque habrán salido de nosotros e incluso las llamaremos "hijos adultos de la Compañía", como ya lo hacemos, pero en realidad serán hijos emancipados y tarde o temprano dejarán la "casa paterna" y ya no serán un aporte para nuestro apostolado.

\subsection{Se precisa a nivel institucional}

Las instituciones necesitan este conocimiento interno para poder tomar decisiones con valentía y con ciertas garantías. Porque las decisiones en favor de la justicia y de los pobres requieren un grado de clarividencia. Los pobres, en un primer momento, son siempre vistos como un problema, a nivel económico, de desarrollo de nuestra actividad e incluso de relaciones. Se necesita mucha convicción interior para tomar de forma consciente resoluciones que les favorezcan.

De otra parte, es ese conocimiento de calidad el que puede ubicar adecuadamente a nuestras instituciones y el que posibilite que el horizonte apostólico al que responden se eleve: con presencia pública, con incidencia política, con interlocución con instituciones públicas y privadas, con ámbitos de Iglesia... Nuestra misión requiere este tipo de presencias.

\subsection{Se precisa a nivel provincial / sectorial}

A mi modo de ver este nivel es mucho más estratégico, pues los sectores y las provincias en que está estructurada la Compañía tienen recursos que las instituciones, por sí solas y por separado, no tienen. Síntesis de las que hablamos posibilitarán que sectorial y provincialmente se puedan identificar nuevos retos, estudiar qué instituciones responderán mejor a ellos y demandarlo, incluso reflexionar sobre si son necesarias nuevas iniciativas apostólicas, o si algunas han dejado de serlo.

Este tipo de reflexión sólo se puede llevar a cabo a nivel de sector o de provincia. Con frecuencia, las instituciones carecen de la libertad interior requerida. Igualmente, precisaremos reunir los recursos humanos valiosos de una o varias provincias para formar una comunidad capaz de discernimiento riguroso.

Es obvio que la misión de fe y justicia necesita interlocución política, con instituciones eclesiales, con organizaciones sociales, relaciones con medios de comunicación, con financiadores... Más aún en una sociedad tan plural como 
la nuestra, que promete serlo aún más en el futuro. Este tipo de relaciones es crucial. Este "conocimiento interno" discernido y consensuado será vital para tener una agenda propia en nuestras interlocuciones. De otra manera, iremos de la mano de los vientos que corran, de las agendas de otros, que tienen su fuerza. Es aquí también donde se ve la importancia de que las síntesis a las que lleguemos estén orientadas a la acción e incluyan posturas, propuestas y recomendaciones.

Creo que si logramos hacer algo de esta tarea, aunque sólo sea un poco, nuestra fuerza apostólica será mucho mayor. Nos proporcionará una mayor solidez, visiones sobre el mundo compartidas (hoy en día muy difíciles), posturas discernidas, firmes y consecuentes. No cabe duda: creceremos como cuerpo apostólico. Me atrevería a decir que este es un alimento espiritual esencial en la dieta del jesuita y de quienes trabajan en este cuerpo, convencidos de esta misión, más aún en las generaciones jóvenes.

De otra parte, este tipo de conocimiento de la realidad será un componente clave para nuestra formación permanente y para la motivación y formación de los laicos que trabajan junto a nosotros.

\subsection{Se precisa a nivel de Compañía}

También se precisa a nivel de Compañía. En tiempos pasados la reflexión de las instancias de gobierno de la Compañía han sido un aliento y un impulso cruciales. Los Padres Arrupe y Kolvenbach han sido dos hombres que nos han ayudado muchísimo con su clarividencia, sabiduría y aportaciones. Hemos de reconocer que no hemos estado a su altura. Sin el apoyo de las instancias más altas del gobierno de la Compañía y sus visiones sobre el mundo, creo que sería muy difícil sostener nuestra misión en el conjunto de la Compañía, porque abundan en nuestro interior fuerzas disgregadoras.

\section{Algunas dificultades actuales}

Repasamos a continuación algunas dificultades que, a mi modo de ver, podrían calificarse de mayores en el despliegue de esta tarea. En primer lugar, -siento mencionarlo pero me parece real-, creo que nos falta el interés suficiente para responder a la misión de fe y justicia, a nuestra única misión. Más de treinta 
años después de haber sido acuñada, hoy vuelve a ser necesario justificarla en muchos foros, como si no terminara de ser cierta. Tal vez las dificultades reales que atraviesan cotidianamente nuestras instituciones nos hacen mirarla con recelo. En el fondo nos hallamos en lo que en Ejercicios llamamos "segundo binario": la opción nos atrae, pero preferimos orillar la conversión que entraña ${ }^{45}$. Tal vez abrumados por la complejidad de lo real, terminamos sucumbiendo a ella y nos recluimos en espacios menos conflictivos.

Otra versión de esta misma dificultad se halla en una impresión extendida en la Compañía según la cual se sigue considerando que unos se dedican a la fe, otros a la cultura y otros más a la justicia. Y que lo más importante, en nuestro ambiente de secularización, serían la fe y la cultura.

En segundo lugar, otro obstáculo consiste en que creemos que en el campo de la reflexión social requerimos jesuitas que brillen para poder llevar adelante nuestro análisis de la realidad. No es así. Si existen, estaremos muy contentos, pero no son imprescindibles. Es más relevante la síntesis sapiencial, en la que la investigación es uno de sus momentos. Habrá personas que no sean jesuitas que podrán aportarnos lo que nosotros ya no tenemos. Tendremos que ser humildes y dejar paso a otros.

Lo que sí precisaremos será maestros que nos guíen en la elaboración comunitaria de un "conocimiento interno", personas de hondura humana, de amplios conocimientos, abiertos a una diversidad de sensibilidades, dialogantes y líderes en discernimiento comunitario.

En tercer lugar, las mayores capacidades para llevar a cabo este tipo de síntesis sapienciales se encuentran en las universidades. Pero éstas tienen sus propias lógicas institucionales. No es fácil que investiguen sobre aquellos campos que consideramos más relevantes, o que se atrevan a una verdadera interdisciplinariedad. La libertad de cátedra y la carrera académica a veces se interponen en este cometido. No deja de ser revelador que el grupo institucional que haya llevado a cabo más elaboraciones sapienciales y divulgativas sobre una enorme diversidad de temas en España haya sido Cristianisme i Justicia, que es

\footnotetext{
${ }^{45}$ CG 34, decreto 3, n. 17: La promoción de la justicia requiere ante todo de nuestra propia y continua conversión para encontrar a Cristo Jesús en la quiebra de nuestro mundo... Nuestra sensibilidad para con esta misión estará tanto más motivada cuanto más frecuente y directo sea nuestro contacto con esos 'amigos del Señor', de cuya fe siempre podemos aprender. Cierta inserción en el mundo de los pobres debe formar parte de la vida de todo jesuita.
} 
universidad de comunidades cristianas, pero no reconocida académicamente, y sin emisión oficial de títulos.

Por otra parte, tengo la impresión de que en nuestra historia reciente no hemos vinculado suficientemente el serio y atinado trabajo de reflexión social realizado por algunos compañeros con el desarrollo de nuestros apostolados. Una generación de intelectuales cristianos de altura, renombre y consideración pública llega en este tiempo a emitir su último canto y no los podremos sustituir. Su contribución, sin embargo, ha quedado más para referirnos a ellos como valores de la Compañía que para tener en cuenta sus aportaciones para redirigir y renovar nuestras instituciones y ministerios. Tal vez porque el análisis lo hemos referido más a nuestra dimensión contemplativa que a la activa. Una investigación orientada preferentemente a desvelar realidades, que a responder a ellas.

Nuestro mayor reto como Compañía en los próximos quince años no va a ser el número. Las estrecheces derivadas de un número decreciente las sobrellevaremos. El mayor reto al que nos enfrentaremos consistirá en el liderazgo apostólico. Puesto que nuestra misión consiste en la fe y la justicia, será crucial que contemos con este tipo de conocimientos sapienciales de la realidad.

\section{Algunos campos de especial interés}

Podemos mencionar algunos campos sociales en los que precisamos de reflexiones lúcidas y de propuestas prácticas. Presentamos un elenco matizable y ampliable de temáticas con el fin de reflejar el calado que requiere el conocimiento ignaciano de la realidad del que hablamos:

- Inmigración e interculturalidad: características de la inmigración; cuestiones de derechos y justicia planteadas; necesidades formativas de las nuevas poblaciones; significados coherentes y legítimos de la integración; papel de la religión y la espiritualidad; necesidades pastorales de los inmigrantes; qué es una escuela intercultural y experiencias exitosas; espacios de intercambio y enriquecimiento mutuo; participación social y política de los inmigrantes; nueva cultura en la que nos vamos adentrando...

- Religión y laicismo: papel de la religión en sociedades plurales; aporte de las instituciones confesionales a estas sociedades; riesgos de la privatización de la religión y límites que debe tener en nuestro cristianismo; qué defensa hoy 
de la dimensión pública de la religión es conveniente y necesaria hacer; qué interlocución y debate se puede establecer con distintas instancias eclesiales; qué reivindicaciones debemos realizar...

- Reconciliación: dimensiones sociales del perdón y la reconciliación; aportación cristiana a la reconciliación y la paz; papel de las víctimas; significado público de las "víctimas reconciliadas"; gestión pacífica de los conflictos; comunidades de paz y reconciliación; aplicaciones para nuestros conflictos comunitarios, sociales, nacionales...

- Globalización cultural e identidades ${ }^{46}$ : cultura hegemónica y erosión cultural; construcción de identidades personales; papel de la escuela; ubicación de las religiones en este contexto como vehículos de identificación; tendencias a la resistencia cultural, el fundamentalismo y el integrismo; propuestas de renovación cultural; posicionamiento de una religión al servicio de identidades mestizas y abiertas...

- Nuevas economías al servicio del desarrollo humano: modelos económicos existentes en la actualidad, posibilidades y riesgos; significados de desarrollo humano y papel de las dimensiones no materiales (simbólicas y espirituales); relación entre economía y desarrollo; posibilidades abiertas para una economía al servicio del ser humano y de las comunidades...

- Procesos de secularización / Experiencia religiosa: qué espacios abren hoy a la experiencia religiosa; cuáles son los agentes disolventes de lo religioso en la actualidad y cómo atajar su influencia; qué tipo de religiosidades son más necesarias; qué instrumentos están más a nuestro alcance; cómo defender la necesidad y plausibilidad de la comunidad cristiana; qué acentos podemos realizar en los distintos ámbitos en los que trabajamos; cómo mostrar la relevancia y racionalidad de la fe en el plano personal, institucional y social...

- Pobreza: procesos globales que empujan a poblaciones enteras a la exclusión y la pobreza; formas de atajarla; legitimaciones públicas de la desigualdad; identificación de los colectivos que son generadores de pobreza; relación

\footnotetext{
${ }^{46}$ P. H. KolveNBACH (2007) Selección de escritos (1991-2007), citado "Alocución en la Reunión Internacional sobre la Educación Superior de la Compañía de Jesús" (Monte Cucco, 27 de mayo de 2001), p. 319: A las universidades corresponde un papel insustituible en el análisis crítico de la globalización, con sus connotaciones positivas y negativas, para orientar el pensamiento y la acción de la sociedad. En lenguaje ignaciano, para descubrir lo que viene del buen espíritu y lo que viene del malo.
} 
entre poblaciones culturalmente rechazadas y exclusión económica; posibles posicionamientos políticos...

La CG35 nos ha sugerido algunos de estos temas y otros más, como la ecología $^{47}$. Pero lo que pretende mostrar esta breve lista de grandes cuestiones es que las temáticas son absolutamente relevantes para nuestra misión y requieren mucho estudio y discernimiento. Si nuestras instituciones no responden a ellas, no podremos decir que están al servicio de nuestra misión. Pero en muchos casos no les será sencillo ubicarse adecuadamente en estas realidades tan complejas. Necesitarán ayuda.

Otra consecuencia que, de pasada, puede verse en el tipo de temáticas que mencionamos es que el esquema mental que aún conservamos de organización por sectores apostólicos queda desbordado. Lo sectorial tiene una orientación hacia la actividad; el planteamiento apostólico en orden a la misión da un vuelco a esta perspectiva.

\section{Un posible modelo}

El siguiente esbozo propone una organización posible de las diferentes piezas que hemos estado mencionando. Las tomamos primero individualmente y a continuación tratamos de incluirlas en un conjunto organizado.

\section{I. La investigación social propiamente dicha}

GRÁFICO 1

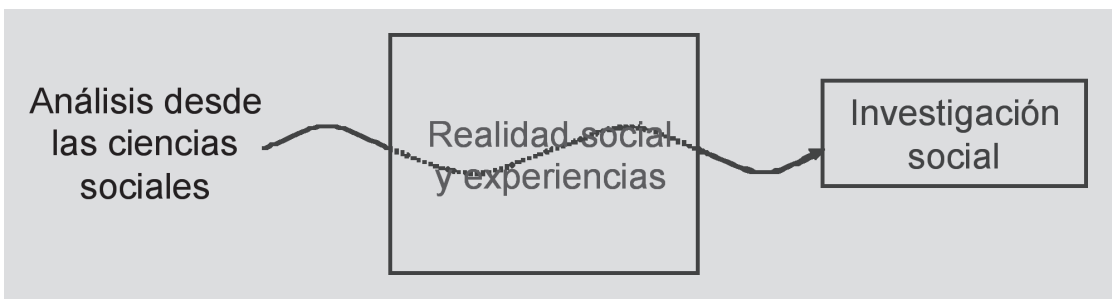

${ }^{47}$ CG 35, decreto 3, n. 35: Esta Congregación urge a todos los jesuitas y a quienes comparten la misma misión, en particular a las universidades y centros de investigación, a promover estudios y prácticas orientadas a enfrentar las causas de la pobreza y a mejorar el medio ambiente. 
Hablamos de una investigación social que se lleva a cabo en universidades y en algunos centros sociales. Algunos análisis necesariamente habrán de ser préstamos de otras disciplinas o procedentes de instituciones que no sean nuestras.

Cuando la investigación esté realizada en nuestras instituciones deberá incluir algunos "acentos ignacianos": la explicitación de los presupuestos de los que se parte y la coherencia en el desarrollo; reconocimiento de las influencias y alianzas afectivas que subyacen; destacar en algún momento un "dejarse afectar". En estos casos, esta investigación debería considerar las experiencias realizadas en nuestros centros sociales y en instituciones de otros sectores ${ }^{48}$. Es decir, la investigación social ignaciana debería incluir algunas características específicas.

Algunos rasgos que tendrá finalmente esta investigación social serán: el rigor y honestidad con lo real, la fragmentación / compartimentación de sus aportes, la necesidad de préstamos no ignacianos. Con frecuencia será fría y complicada de seguir.

Como puede comprobarse, en mayor o menor medida, esta investigación ya se está haciendo o estamos en condiciones de realizarla.

\subsection{La reflexión social de nuestros centros sociales}

También nuestros centros sociales realizan su propia reflexión sobre la realidad. Aprenden de su experiencia, de las situaciones ante las que se encuentran y que meditan muchas veces de una forma sistemática, y en otras ocasiones, de modo más libre. También hacen uso de lecturas o aportaciones que reciben de algunos analistas sociales.

Algunas características de esta reflexión de la experiencia es que es apasionada, a veces puede preferir el eslogan al rigor. Y si bien se centra en una única parcela de la realidad, ante ella su acercamiento es holístico, recogiendo una diversidad de perspectivas y disciplinas.

${ }^{48}$ Las Normas Complementarias, citadas, n. $293 \S 2$ piden a quienes lleven a cabo el apostolado intelectual que no pierdan contacto con las demás actividades apostólicas y cooperen con los que se dedican a ministerios más directamente sociales y pastorales. 


\section{GRÁFICO 2}

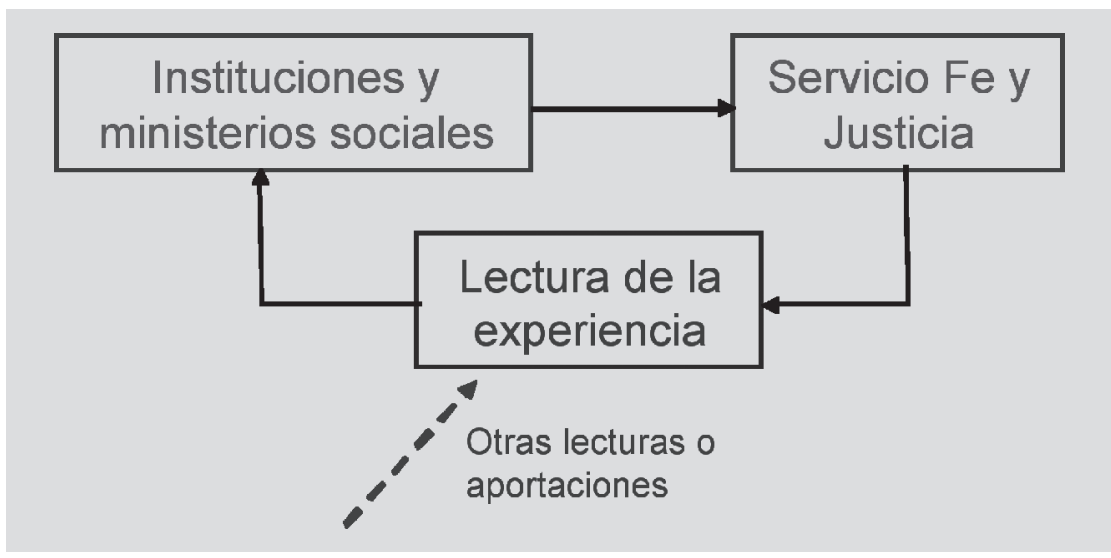

\subsection{Conocimiento ignaciano de la realidad}

El conocimiento ignaciano de la realidad debe partir de los dos elementos anteriores para alcanzar sus propias síntesis. Será realizado en una comunidad de discernimiento, en la que habrán de participar tanto personas que realizan el análisis de la realidad como aquéllas que parten de las experiencias de los centros sociales.

Ya hemos señalado algunos cometidos de este conocimiento ignaciano:

1) recoger análisis interdisciplinares, elaborados sobre datos e investigaciones rigurosas ${ }^{49}$; con apertura a lo real, a su sorpresa y su novedad.

2) construirse también desde experiencias que puedan compartirse;

3) dejarse afectar por la realidad, detectando dónde sufre más la humanidad y dónde se abren puertas de esperanza;

\footnotetext{
${ }^{49}$ CG 34, decreto 26, n. 20: En el contexto de los complejos retos y oportunidades de nuestro mundo contemporáneo, nuestro ministerio requiere toda la erudición e inteligencia, imaginación y perspicacia, estudios sólidos y análisis rigurosos que podamos acumular. También en CG 34, decreto 16, n. 3: para que la evangelización sea eficaz, son imprescindibles rigor en el conocimiento, respeto hacia los demás en el diálogo intercultural y análisis crítico.
} 
4) incorporar una lectura teológica;

5) ser el fruto de un discernimiento honesto - desvelando nuestros intereses ocultos y complicidades-, centrado en el Reino y los pobres y realizado en común;

6) estar orientado a la práctica generando planteamientos y propuestas; con creatividad y audacia ${ }^{50}$;

7) elaborar modos de divulgación razonable y creíble que nos ayuden a todos en la formación permanente y a limente nuestras motivaciones profundas $y$ afectos, alentando también nuestra fe;

8) establecer una agenda de interlocución con agentes sociales, eclesiales y políticos $^{51}$.

También hemos indicado que necesitará de metodologías adecuadas y de maestros que piloten los procesos de búsqueda.

\subsection{Al servicio del liderazgo apostólico}

Presentamos a continuación cómo quedaría un esquema final organizado con todos los elementos que hemos mencionado:

50 P. H. KolvenBACH (1991) Selección de escritos 1983-1990, citado "Alocución a la Congregación de Procuradores, sobre el estado de la Compañía" (Roma, 3 de setiembre de 1987), p. 199: Nuestro compromiso no debe ser medido por las palabras, sino por las obras: solamente con esa condición se libra del peligro de quedar reducido a un puro eslogan o a una ideología a la moda, y llegará a encarnar el amor preferencial de Dios mismo a los pobres.

${ }^{51}$ CG 35, decreto 3, n. 28: La complejidad de los problemas que encaramos y la riqueza de las oportunidades que se nos ofrecen piden que nos comprometamos en tender puentes entre ricos y pobres, estableciendo vínculos en el terreno de la incidencia política para la colaboración entre aquellos que detentan el poder político y aquellos que encuentran dificultad en hacer oír sus intereses. Nuestro apostolado intelectual nos proporciona una ayuda inestimable para establecer estos puentes... 


\section{GRÁFICO 3}

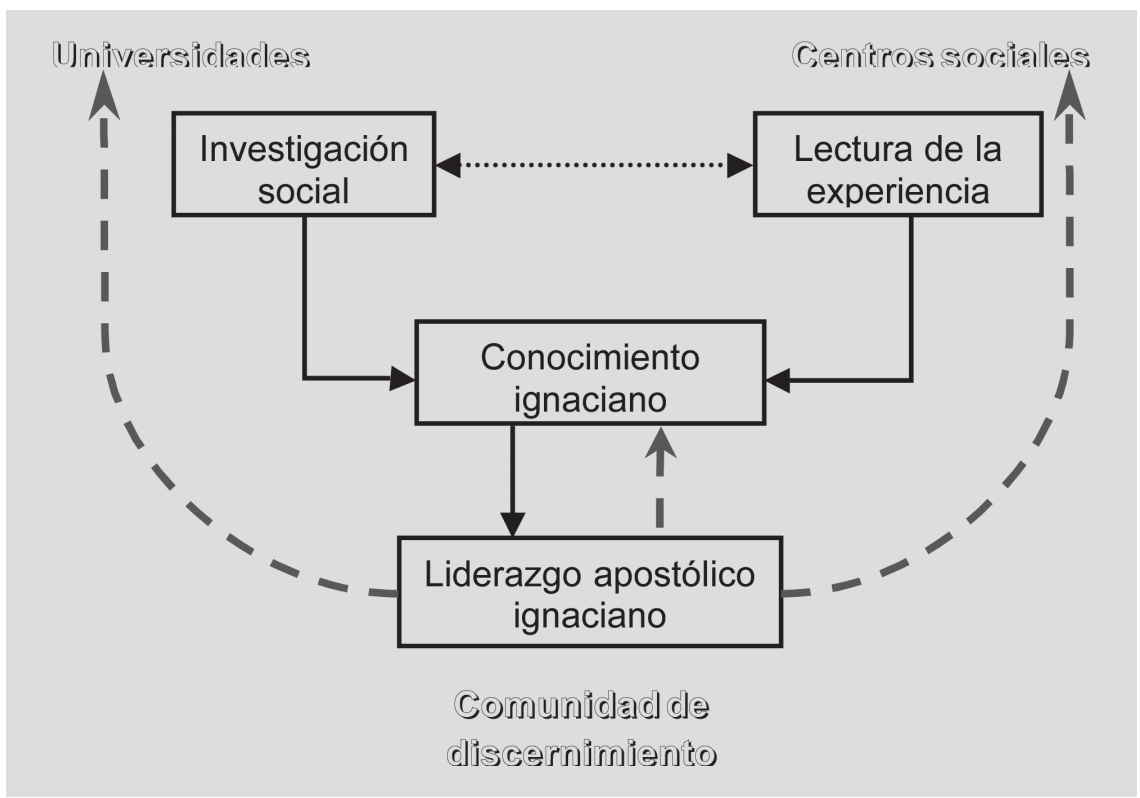

El esquema recoge varios aspectos que deberían subrayarse:

1) la necesidad de colaboración entre los ámbitos universitarios y los centros sociales;

2) el servicio que prestan al conocimiento ignaciano sobre la realidad;

3) cómo el conocimiento ignaciano debe ayudar a un mejor liderazgo apostólico. Esto significa que los ámbitos de liderazgo se han de sentir interpelados por las lecturas de la realidad que broten del conocimiento ignaciano. Si esto no sucede, el esquema se desinflaría pronto por no adquirirse compromisos;

4) el elemento tractor de todo el proceso debe ser el ámbito de liderazgo apostólico. Es el que tiene la capacidad para organizar agendas, solicitar estudios y tomar decisiones a partir de ellos. Sin él el esquema no funciona.

Podríamos preguntarnos: ¿̇para qué tanto montaje?, ¿̇no basta con un buen equipo de liderazgo apostólico, que conozca la realidad y tome decisiones? En realidad esto es cierto. Probablemente así se haya hecho durante mucho tiempo. 
Pero hoy este es un ideal inalcanzable. No hay personas que conozcan los estudios y las experiencias, sean capaces de valorar y discernir su importancia y después tengan la potestad de tomar decisiones sobre obras y personas. Pensar que esto es factible es ilusión, puro espejismo. La realidad y nuestros ministerios son ya demasiado complejos para que unas pocas personas puedan responder a todos estos requerimientos.

Sin embargo, esta reflexión sí da pie a pensar que habría personas que deberían estar en varios de estos ámbitos. Tendría que haber personas de la academia y de los centros sociales en el ámbito de elaboración del conocimiento interno de la realidad, así como personas concretas que, participando en los ámbitos de liderazgo, lo hicieran también en el discernimiento del conocimiento. Con ello se lograría empatar mucho más el engranaje.

En resumen, la investigación social constituye un elemento muy importante hacia las síntesis sapienciales sobre la realidad que hoy necesitamos si queremos responder de forma más adecuada a nuestra misión por la fe y la justicia. Es ahí donde puede hoy encontrar su ubicación más adecuada. 